\title{
The Impact of Participation in the Belt and Road Initiative on the Tourist Flows
}

\author{
Artur Kuchumov \\ Department of Economics and Management in the Sphere of \\ Services \\ Saint-Petersburg State University of Economics \\ Saint Petersburg, Russia \\ arturspb1@yandex.ru
}

\author{
Yana Testina \\ Department of Country Studies and International Tourism \\ Saint-Petersburg State University \\ Saint Petersburg, Russia \\ y.testina@spbu.ru
}

\begin{abstract}
The article discusses the changes taking place in the geo-economics of Eurasia associated with the creation of the People's Republic of China One Belt One Road initiative in 2013. These changes are linked with globalization, increased exportimport dependence and with the forecast of an increase in mutual tourist flows between the countries involved in the program. We present potential problems and development perspectives of One Belt One Road initiative and investigate the impact of participation in the Belt and Road Initiative on the economy and tourism industry of the Russian Federation.

The relevance of the topic lies in the fact that there are differences in socio-demographic, political, economic, naturalgeographical and other conditions in most regions of Russia and other countries implementing the program "One Belt One Road", which excludes a unified approach to the development of tourism there. These differences require a sound policy of socioeconomic development based on a differentiated approach to different types of regions, depending on their level of economic maturity, social and environmental situation, and specialization. Tourism is inherently linked to specific resources, natural and geographical factors, regional characteristics and therefore needs a broad decentralized organization, primarily on a regional basis, which, however, is supposed to implement the same concept of increasing reciprocal tourist flows.

The scientific justification of the development of tourism under the One Belt One Road program involves solving the problem of integrated development of infrastructure support for regional tourism and hospitality systems. This article proposes a solution to the lack of sound methods for estimating its level of development, due to the lack not only of adequate tools, but also of a statistical base that allows to obtain up-to-date information. An information base has been developed to monitor, assess and rank regions to determine whether the level of funding for tourism infrastructure development is optimal.
\end{abstract}

Keywords: People's Republic of China, One Belt One Road, the Belt and Road Initiative, economics, tourism

\section{INTRODUCTION}

Currently, China's economic policy of cooperation with various countries has received a new round of development, which is based on the creation of the One Belt One Road initiative. The project has a number of commonly used names: The Belt and Road Initiative (BRI) [1], The Belt and Road, The Silk Road Economic Belt [2] and New Silk Road [3].

"One Belt, One Road" is the shortened name of the economic belt "The Great Silk Road" and "Sea Silk Road of the 21st Century" (Figure 1), which have existed for a long time.

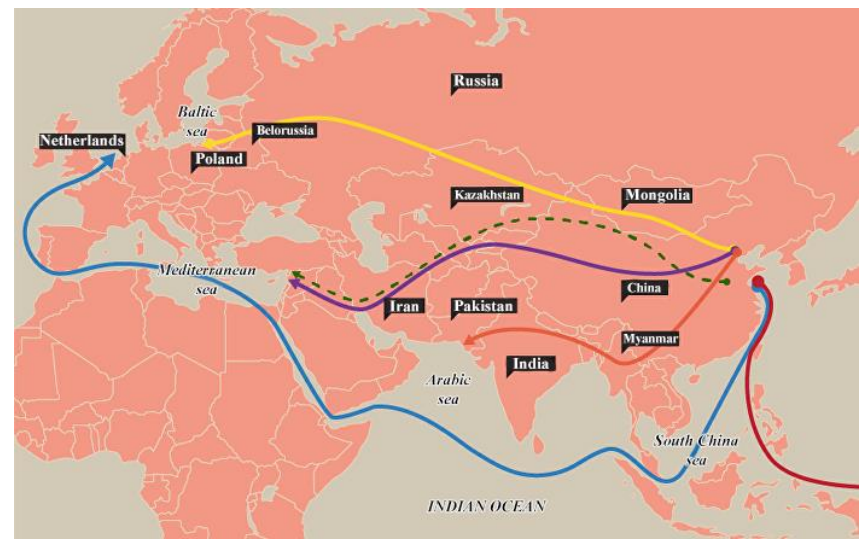

Fig. 1. Map of the location of trade routes

In the past, the Great Silk Road, from the city of Xi'an in the east to the city of Constantinople of the Roman Empire in the west, passed through the Gansui Corridor and connected with Eurasia. Its great history begins with the Han Dynasty and reaches its heyday under the Tang Dynasty. At sea, the "Great Silk Road" for shipping began with the Han Dynasty or earlier. 
These routes were a transport communication connecting East and West on land and at sea, uniting Eastern and Western culture, and being a symbol of socio-cultural exchange between China and the West in ancient times. The "Great Silk Road" currently has three directions:

- from northwestern China, through northeastern Central Asia, Russia and to the Baltic Sea in Europe;

- from the northwestern China, through Central Asia, West Asia to the Persian Gulf and the Mediterranean;

- from southwestern China through the Indo-Chinese Peninsula to the Indian Ocean.

"Sea Silk Road" today has two directions:

- from the seaside ports of China on the South China Sea, through the Strait of Malacca and the Indian Ocean to the European mainland;

- from the seaside ports of China on the South China Sea to the South Pacific.

In the future, it will depend entirely on a multilateral mechanism that includes China and other States working together on the basis of a mechanism of inter-regional cooperation.

"One Belt, One Road" is used by China as a historical symbol of the "Great Silk Road", an example of peaceful trade and economic development, active economic cooperation with nearby states, joint formation of mutual political trust, economic integration, common cultural interests, a community of common destiny and a system of obligations.

China has supported the BRI since 2013 [2]. The Belt and Road has focused on the need to transform infrastructure, trade and economic arrangements along the New Silk Road route, which provides significant opportunities for the sustainable development of the countries [4]. During the last five years, China has signed cooperation agreements with 69 countries and international organizations, and many of them are related to cooperation in tourism [5].

Tourism is one of the industries most benefiting from the initiative. According to the latest report on tourism in China, the number of trips of Chinese tourists to the BRI countries increased from 15.5 million people in 2013 to more than 27 million people in 2017. The increase has been 77 per cent over the past five years. In addition, tourists from countries along the One Belt One Road route made10.6 million trips to China in 2017, compared with 9 million in 2013. They have brought in $16.9 \%$ of the gross income of China this year, which amounted to 123.4 billion USD [5].

The development of BRI will lead to an increase in mutual tourist flows, including the established Belt and Road Hospitality Fund [6], which will help to invest in the development of the tourism and hospitality industry in the countries participating in the One Belt One Road.

Tourist companies of the Celestial Empire are actively developing and opening new routes for tourists, improving popular destinations on One Belt One Road and providing more and better service. At the same time, the governments of the concerned countries implementing the strategic initiative are taking comprehensive measures to simplify the procedures for issuing tourist visas and provide various preferences for the development of new routes, hoping to increase reciprocal tourist flows [7]. Tourism industry participants are pleased to note that the One Belt One Road economic development initiative has not only significantly revitalized China's outbound tourism market, but also, at the same time, stimulated the market for inbound tourism to China [8].

BRI attracts a wide range of mass and business communities in all countries and regions of the world. Chinese tourists care whether they will be able to travel to countries along the "One Belt, One Road" in the future and learn about the customs and culture there, as in some regions there is no necessary tourist infrastructure [10]. The article describes the methods of ranking tourist infrastructure at the mesolevel.

\section{METHODS}

Cooperation between China and Russia in the tourism sector developed over several stages, its main trend was a gradual expansion of scale, tourist products were becoming more diverse every day, channels were regularly expanding, mechanisms were constantly improving. To better understand the processes of tourism development, it is necessary to turn to the history of Sino-Russian tourism.

\section{A. Initial stage (1987-1991)}

In the $80 \mathrm{~s}$ of the 20th century, the number of tourists from the USSR coming to China to travel was small, in 1987 it was only 24,794 people, and the USSR ranked 12 th out of 15 among the main sources of guests for China. In early 1988, Heihe District in Heilongjiang Province was the first in the border area to open a "one-day Heihe-Blagoveshchensk tour", followed by a "seven-day trip from Harbin to the USSR," a "one-day trip from Tonjiang to the village of Nizhneleninsky," a "one-day trip Suifenhe-the border village Pogranichny" and other tourist lines. After that, the number of tourists from both countries taking part in "one-day tours" suddenly increased. In 1990, tourists from the USSR ranked third in terms of the number of foreign tourists coming to China, becoming the third largest country, the flow of tourists from which exceeded a million visits per year [11]

At this stage, the scale of cooperation between China and Russia in the tourism sector was small, as the main tourist product was "one-day border tours".

\section{B. Development stage (1992-2007)}

After the collapse of the Soviet Union, Russian economy began to transform and at some point plunged into a state of crisis, the country was extremely lacking clothing, shoes, hats and other products of light industry, as well as household items, buyers-tourists from Russia rushed China, setting off a boom in "tourist trade."

In 1992, the governments of China and Russia signed an "Agreement between the Government of the People's Republic of China and the Government of the Russian Federation on Mutual Exemption from Group Tourist Visas", which 
facilitated the development of the China-Russia cross-border tourism. In the second half of 1993, China and Russia canceled the visa-free regime agreement, which led to the fact that in 1994 and 1995 trade and economic cooperation between China and Russia entered a period of recovery; however, border tourism in both countries has not received too much development. During 1996-2008, the number of tourists entering China continued to increase rapidly, Russia was in fourth place in terms of the number of tourists who entered. In 1998, five provinces of China-Heilongjiang, Liaoning, Jilin, Autonomous Regions of Inner Mongolia and Xinjiangreceived $75.32 \%$ of Russian tourists who came to China.

In August of 2005, after China's cross-border tourism was cancelled across the country, trips to the border area of the Heihe district were largely stagnant. On February 26, 2006, Russia adopted a new customs policy, according to which individuals of Russia were exempt from paying taxes on goods at the entrance to the country, but the terms and weight restrictions changed, the original period of once a week was replaced with once a month, the weight decreased from $50 \mathrm{~kg}$ to $35 \mathrm{~kg}$. Such measures have led to an increase in the cost of buying goods during the border shopping tourism of China and Russia through Suifenhe, and the number of people entering China has decreased markedly.

This stage of Sino-Russian tourism includes such a feature as "shopping tourism", then the scale expands to border resort trips and border trips on tours. Due to the impact of the cancellation of cross-border tourism, Sino-Russian tourism has been restricted to travel from the border areas to the interior of the country and along the coast, including destinations such as Beijing-Loyang, Beijing-Xi'an, Beijing-Sanya, which are now considered by Russian tourists as tourist routes with Chinese goods of the highest quality, and Hainan and Sanya have already become holiday destinations for Russians.

\section{The downturn between China and Russia in tourism (2008-2010)}

In 2008, Russian tourists came to China about 2,130,000 times, which is about $41 \%$ less than during the previous year.

\section{The stage of restoring and developing relations between China and Russia in the field of tourism (2011 - to date)}

China and Russia have now become important tourist destinations for each other. Due to the drop of the ruble, Russia has become a country where you can buy goods at low prices, so tourists from China rushed to Russia. Attractive for tourists were such goods as gold jewelry, wristwatches, amber, honey and all sorts of alcoholic beverages [12].

Reciprocal tourist flows are constantly increasing (Figure 2-3), which leads to the need to create new and transform existing tourist products to meet the needs of both sides.

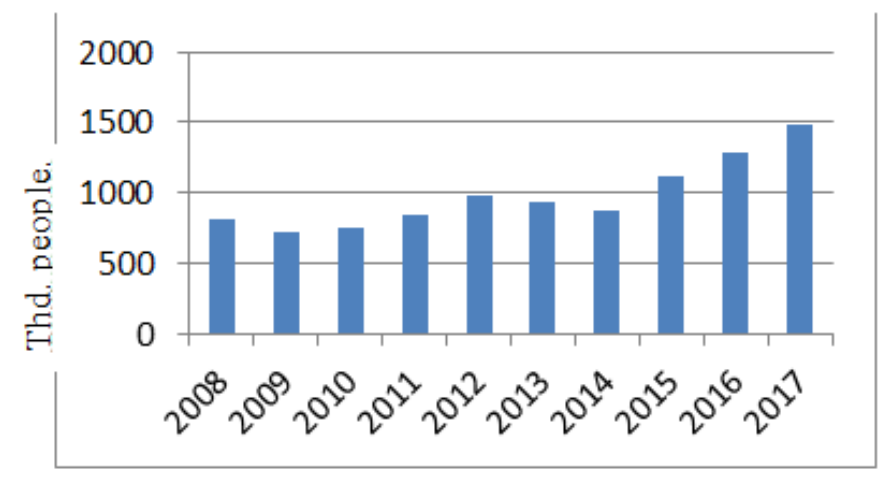

Fig. 2. Dynamics of thenumber of tourists who left China for Russia with different goals in 2008-2017, thousands of people [Composed by authors according to 13]

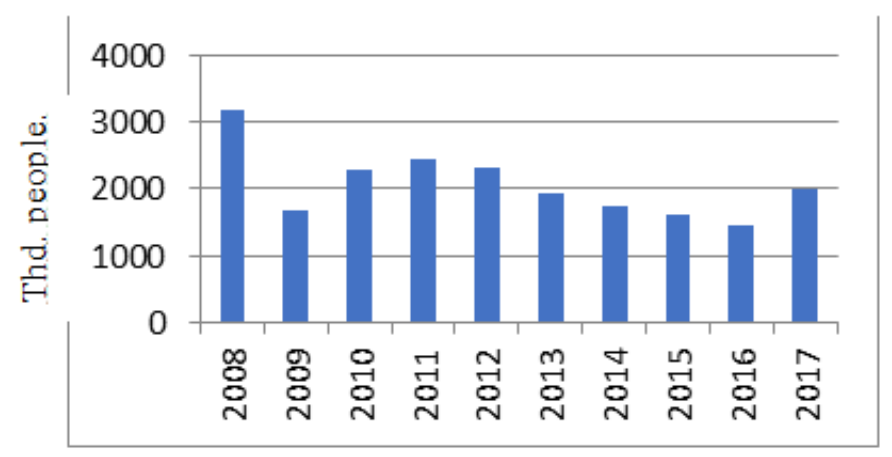

Fig. 3. Dynamics of the number of tourists who left for China with different goals in 2008-2017, thousands of people [Composed by authors according to 13]

Figure 2 shows an increase in the tourist flow of Russian tourists to China after a prolonged decline in 2012-2016. China ranks $3 \mathrm{rd}$ in the number of inbound tourists after Ukraine and Kazakhstan. Based on the data of Figure 3, we can conclude that there has been a steady increase in the outbound tourist flow to China.

The increase in mutual tourist flows with China is also shown by European countries. More than 7 out of 10 overnights of residents from China in the EU were spent in four countries: The United Kingdom (31\%), Italy (18\%), France (13\%) and Germany (10\%) (Figure 4). 


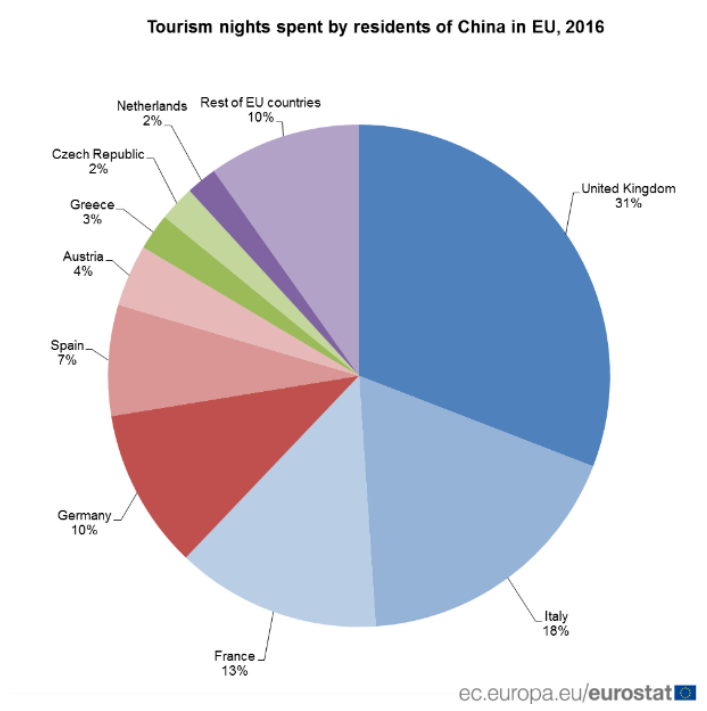

Fig. 4. Tourism night spent by residents from China [14]

Within the Asian market, China is the third most popular destination for EU tourists (13.7\%) and EU tourists (13.7\%). (Figure 5).

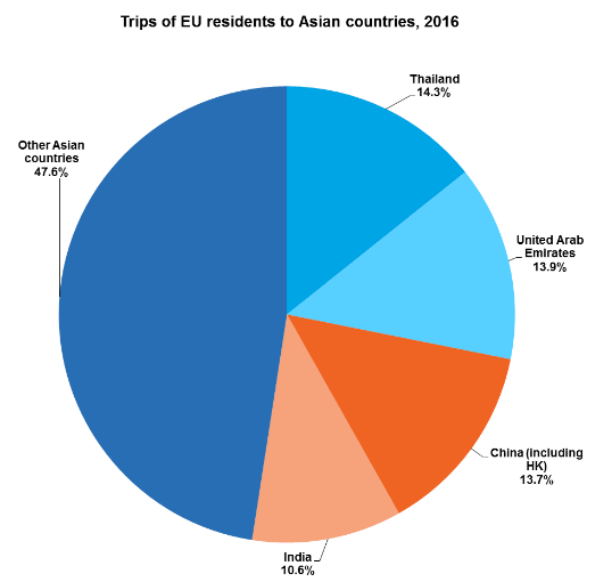

Fig. 5. Trips of EU residents to Asian countries in 2016

The growth of the inbound tourist flow from China can be attributed to the following trends in the interrelationship of countries in the field of tourism:

1. Improvement of quality of Russian tourist products offered to Chinese tourists.

2. Development of infrastructure of popular tourist destinations, as tourists from China are quite demanding when it comes to quality of accommodation facilities.

3. Increased cultural engagement, use of event marketing mechanisms.

4. Involving "new" Russian tourist destinations in the already familiar routes for their diversification.

5. Promotion of new routes based on trade routes: New Silk Road (One Belt, One Road), Great Tea Road.
6. The introduction of the "China Friendly" program in the hospitality industry.

We need to note that the most popular destinations for tourists from China are the following cities: Moscow, St. Petersburg, Murmansk, Irkutsk and the Kamchatka Peninsula. However, under the influence of the Belt and Road Initiative, tourist flows can be redistributed, increasing the number of tourists on the territory of New Silk Road, which will lead to the unloading of popular tourist centers, optimization of tourist flows, and leveling seasonality factors in the future.

One of the main problems preventing the increase in mutual flows is the state of the regional tourist infrastructure.

The management of regional tourism infrastructure requires adequate information support, but regular statistical reporting in tourism is now provided by the Federal Office for State Statistics in insufficient volume and untimely. This does not allow to fully address the critical task of ensuring consistency of the executive branch at the federal and regional levels, including the preparation of proposals and pre-project solutions for the development of domestic and inbound tourism in Russia [15].

The methodology of the study was based on the results of the study by A.V. Kuchumov [16], who singled out systemforming elements (tour operators, travel agents, hotels and other accommodation facilities) and infrastructure elements (institutional infrastructure-security, transport, service, information research, production, and financial and investment infrastructure)in the regional tourism system.

In Table I, we will present the information base needed to assess and rank regions to finance tourism infrastructure. This will allow the optimization of regional financial macro and meso-economic policies to attract tourists to the regions. The mechanisms for assessing the regional infrastructure of tourism should be applied not only in Russia and China, but also in other regions participating in the Belt and Road project. 
region's population"; "Number of road accidents per 100,000 people of the region's population"; "Dumping contaminated wastewater into surface water bodies, thousands of tons"; "Emissions of pollutants into atmospheric air from stationary sources, thousands of tons": in accordance with their role in providing comfortable living conditions in the region, rank 1 is assigned to the lowest value, the next lowest gets rank 2, etc. [17].

An assessment of the $S_{i}$ level of tourism infrastructure development in the region is calculated as follows (2):

$$
S_{i}=\sqrt{\sum_{j}^{n}\left(1-r\left(y_{i j}\right)\right)^{2}},
$$

where $y_{i j}$ is the ${ }^{j}$ th indicator-characteristic of the infrastructure

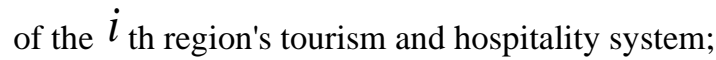

$r\left(y_{i j}\right)_{\text {is }}$ the rank of $j_{\text {th indicator of the tourism }}$ Information and research telematics services, thousands of units.

\begin{tabular}{l|l} 
infrastructure & Number of staff engaged in research and
\end{tabular} development, people.

Distribution of the number of enterprises and organizations by types of economic activity: construction, provision of infrastructure, social and personal services, hotels and restaurants, units.

Volume of works carried out by the type of economic activity "Construction," million rubles.

Investments in fixed capital by types of economic activity: hotels and restaurants, million rubles.

Financial and investment infrastructure

Foreign investment in the Russian economy, thousands of U.S. dollars.

Dumping contaminated wastewater into

Environmental surface water bodies, thousands of tons.

infrastructure

Emissions of pollutants into atmospheric air

from stationary sources, thousands of tons

A two-dimensional criterion (1) was used to determine the rating of the Russian region's level of tourism infrastructure development.

$$
R\left(r_{i}^{s}, r_{i}^{\mathrm{inf}}\right)
$$

where $r_{i}^{s}$ is the rank of the $i_{\text {th region among the regions of the }}$ Russian Federation in terms of the indicator that characterizes the system-forming elements of the regional tourism system "Volume of hotel $y_{i}^{l}$ and restaurant services" (Table I);

$r_{i}^{i n f}$ is he rank of $i_{\text {th }}$ region by the indicator "Evaluation of the infrastructure of the regional tourism industry".

Rankings are set in descending order; the highest rank is ranked 1 , the next rank 2 , etc. The exception are the indicators "Number of reported crimes per 1,000,000 people of the infrastructure element of the $i_{\text {th region, }} j=\overline{1, n}$;
$n$ is the number of regions.

In studying the magnitude and dynamics of the assessments received, we have raised the question of their variability. Most of the infrastructure development of regional tourism and hospitality systems is capital intensive and therefore long-term. Therefore, the proposed grouping features can only be used if the region is categorized as a stable zone.

A variation factor was used to assess variability, which is calculated as the ratio of the standard deviation to the average and shows the degree to which the received values deviate from the average (3).

$$
V=\frac{ \pm \sigma}{\bar{x}} * 100 \%
$$

Where $V$ is the variation factor;

$\bar{x}_{\text {is }}$ the average expected value of the indicator.

The variation factor is relative, it varies in the range of 0 to $100 \%$. The higher the value of this ratio, the more fluctuating it is. The following qualitative scale has been established, which allows to interpret different values of the variation factor:

- 0 to $10 \%$ - low fluctuations;

- 10 to $25 \%$-moderate fluctuations;

- over $25 \%$ - high fluctuations.

This assessment is necessary for use in strategic tourism development projects. However, a differentiated approach to the development of selected tourism infrastructure objects and their groups is needed, as the sustainability of changes in the 
parking lots, road signs. there needs to be a replacement for transport that serves the tourism industry.

\section{CONCLUSIONS}

Differentiation of regions involved in the Belt and Road Initiative in terms of the value of the level of development of tourism infrastructure allows to determine priorities and develop management decisions on the direction of infrastructure development.

The different variability of indicators, which characterize different groups of infrastructure elements, raises the question of different planning periods for the development of the sites concerned. Thus, in the future study it is advisable to clarify how the timing and intensity of financing infrastructure projects in the region affects the fluctuating of indicators characterizing institutional and financial-investment, service and information research, production and environmental group of infrastructure elements of the regional tourism system.

The study presents the development of a methodical approach to zoning infrastructure of regional tourism and hospitality systems in areas that differ in the rating of the level of infrastructure development and the volume of tourist services provided-various regions of Russia and other countries that participate in the implementation of the strategic program "One Belt, One Road." At the same time, the main types of infrastructures that ensure the development of the regional tourism system were established: institutional, financial-investment, information-research, socio-cultural, personnel, transport, industrial, environmental, service infrastructure.

The concept of rating assessment of the level of infrastructure development of the regional tourism and hospitality system, based on the ranking of levels of specific characteristics of the development of different types of infrastructure at the mesoeconomy level, is justified. We substantiate the feasibility of zoning the infrastructure of regional tourism and hospitality systems based on the use of a two-dimensional criterion, the value of which is dependent on two grouping features: the rank of hotel and restaurant services located in the region and assessing the infrastructure of the regional tourism and hospitality system.

The results of the work can be used for the design of strategic tourism development plans in the BRI countries in order to improve the quality of tourism infrastructure and to increase mutual tourist flows.

\section{REFERENCES}

[1] Baik Jiwoon, "One Belt One Road" and the geopolitics of empire, Inter Asia Cultural Studies, vol. 20:3, 2019, pp. 358-376, DOI: 10.1080/14649373.2019.1649013.

[2] Raffaello Pantucci, "China in Central Asia: the first strand of The silk road economic belt", Asian Affairs, vol. 50:2, 2019, pp. 202-215, DOI: 10.1080/03068374.2019.1622930.

[3] Brenda Goh and Mariya Gordeyeva, "Shuttered at Home, Cement Plants Bloom Along China's New Silk Road", Reuters, vol. 30(1), 2019.
For efficient and rapid movement of tourists there is not enough accompanying infrastructure: roadside cafes, hotels, 
[12] 中国赴俄旅游游客数量大幅增加物美价廉成主因 http://world.huanqiu.com/exclusive/2015-02/5661457.html

[4] Huadong Guo, Jie Liu, Yubao Qiu, Massimo Menenti, Fang Chen, Paul F. Uhlir, Li Zhang, John van Genderen, Dong Liang, Ishwaran Natarajan, Lanwei Zhu and Jiuliang Liu, "The Digital Belt and Road program in support of regional sustainability", International Journal of Digital Earth, vol. 11:7, 2018, pp. 657-669, DOI: 10.1080/17538947.2018.1471790.

[5]陈溯中国出境到“一带一路”沿线国家游客人次五年间增长 $77 \%$ China's Tourism Development: Analysis and Forecast (2018-2019) https://www.yidaiyilu.gov.cn/xwzx/gnxw/76899.htm.

[6] Chai Hua, "Tourism boom benefits Belt and Road" https://www.chinadailyhk.com/articles/125/205/143/1531723300420.ht $\mathrm{ml}$.

[7] H. Pechlaner, H. Thees, W. Manske-Wang, A. Scuttari, "Local service industry and tourism development through the global trade and infrastructure project of the New Silk Road - the example of Georgia", The Service Industries Journal. 1-27, 2019.

[8] Y.Y. Chang, "Understanding the Belt and Road Initiative (BRI)", European Journal of East Asian Studies, vol. 18, 2019, pp. 7-35.

[9] Diaz Campos, Ivan, "One Belt \& One Road: Between Cooperation and Geopolitics in the Silk Road", Contacto Global, vol. 6, 2015, pp. 18-25.

[10] Eddassi, Hassane, "China's Belt and Road Initiative (BRI)", 2019, 10.13140/RG.2.2.16285.56805.

[11] Guo Li, etc., Sino-Russian humanitarian cooperation: Past and Present", Harbin: Heilongjiang daxuechubanshe, vol. 10, 2013.

[13] Selective statistical information calculated in accordance with the official statistical methodology for estimating the number of entry and exit tourist trips. The official website of the Federal Agency for Tourism of the Ministry of Culture of the Russian Federation http://www.russiatourism.ru/contents/statistika/statisticheskiepokazateli-vzaimnykh-poezdok-grazhdan-rossiyskoy-federatsii-igrazhdan-inostrannykh-gosudarstv/vyborochnaya-statisticheskayainformatsiya-rasschitannaya-v-sootvetstvii-s-ofitsialnoy-statisticheskoymetodologiey-otsenki-chisla-vezdnykh-i-vyezdnykh-turistskikh-poezdok

[14] Tourism from China to the EU more than tripledhttps://ec.europa.eu/eurostat/en/web/products-eurostat-news//DDN-20180118-1

[15] N.A. Karpova, L.B. Maksanova, "Problems of improving tourism management at the regional level [Text]", Bulletin ofSt. Petersburg State Economic University, vol. 4(100), 2016, pp. 87-93.

[16] A.V. Kuchumov, E.E. Sharafanova, Methodical aspects of zoning regional tourism systems: Monograph, 2014, p.155.

[17] G.A. Karpova, A.V. Kuchumov, M.V. Voloshynova, Y.S. Testina, "Application of a balanced system of indicators as an element of control at an innovative enterprise", Journal of Legal and Economic Research, vol. 3, 2018, pp. 157-162.

[18] N.S. Martyshenko, Y.A. Popov, "The new stage of development of economic cooperation of Primorye and China", Azimut research: economics and management, vol. 6(2-19), 2018, pp. 191-195. 